Article

\title{
The Effect of Donor and Nonfullerene Acceptor Inhomogeneous Distribution within the Photoactive Layer on the Performance of Polymer Solar Cells with Different Device Structures
}

\author{
Yaping Wang ${ }^{1} \mathbb{C}^{\mathbb{D}}$, Zhenzhen Shi ${ }^{1}$, Hao Liu ${ }^{1}$, Fuzhi Wang ${ }^{1}$, Yiming Bai ${ }^{1} \mathbb{C}^{\mathbb{D}}$, Xingming Bian $^{1}$, \\ Bing Zhang ${ }^{1}$, Tasawar Hayat ${ }^{2,3}$, Ahmed Alsaedi ${ }^{3}$ and Zhan'ao Tan ${ }^{1, *}$ \\ 1 State Key Laboratory of Alternate Electrical Power System with Renewable Energy Sources, North China \\ Electric Power University, Beijing 102206, China; wyp614725@163.com (Y.W.); shizz123@126.com (Z.S.); \\ dylht00@126.com (H.L.); wfz501@ncepu.edu.cn (F.W.); ymbai@ncepu.edu.cn (Y.B.); \\ bianxingming@ncepu.edu.cn (X.B.); mpezb310@gmail.com (B.Z.) \\ 2 Department of Mathematics, Quiad-I-Azam University, Islamabad 44000, Pakistan; tahaksag@yahoo.com \\ 3 NAAM Research Group, Faculty of Science, King Abdulaziz University, Jeddah 21589, Saudi Arabia; \\ aalsaedi@hotmail.com \\ * Correspondence: tanzhanao@ncepu.edu.cn
}

Received: 12 September 2017; Accepted: 31 October 2017; Published: 3 November 2017

\begin{abstract}
Due to the inhomogeneous distribution of donor and acceptor materials within the photoactive layer of bulk heterojunction organic solar cells (OSCs), proper selection of a conventional or an inverted device structure is crucial for effective exciton dissociation and charge transportation. Herein, we investigate the donor and acceptor distribution within the non-fullerene photoactive layer based on PBDTTT-ET:IEICO by time-of-flight secondary-ion mass spectroscopy (TOF-SIMS) and scanning Kelvin probe microscopy (SKPM), indicating that more IEICO enriches on the surface of the photoactive layer while PBDTTT-ET distributes homogeneously within the photoactive layer. To further understand the effect of the inhomogeneous component distribution on the photovoltaic performance, both conventional and inverted OSCs were fabricated. As a result, the conventional device shows a power conversion efficiency (PCE) of $8.83 \%$ which is $41 \%$ higher than that of inverted one $(6.26 \%)$. Eventually, we employed nickel oxide $\left(\mathrm{NiO}_{x}\right)$ instead of PEDOT:PSS as anode buffer layer to further enhance the stability and PCE of OSCs with conventional structure, and a promising PCE of $9.12 \%$ is achieved.
\end{abstract}

Keywords: organic solar cells; inhomogeneous distribution; non-fullerene photoactive layer; nickel oxide; anode buffer layer

\section{Introduction}

Bulk-heterojunction organic solar cells (BHJ-OSCs) attract increasing attention due to their characteristics of light-weight, low-cost, flexibility, rapid energy payback time and high-throughput roll-to-roll manufacturing [1-3]. Great efforts have been made in the development of new electron donors [4] and acceptors [5], the optimization of morphology [3], clean synthetic methods for the semiconductors production [6] and the engineering of device structure [7], resulting rapid promotion of the power conversion efficiency (PCE) of the OSCs. The PCE of fullerene-based OSCs is over $11 \%$. However, further improvement in fullerene-based OSCs is facing great challenge due to their large energy losses. Recently, non-fullerene small molecules and all-polymer (using a $p$-type donor polymer and an $n$-type acceptor polymer) solar cells have emerged. Compared with fullerene derivatives, non-fullerene $n$-type small molecule and polymer acceptors can be flexibly designed to match the 
donor polymer in molecular weight, absorption spectra and energy level, allowing a better device performance [8-11]. Up to date, the PCE of non-fullerene acceptor based devices has exceeded 13\% [5].

The photoactive layers in OSCs are commonly fabricated by casting the blend solution of electron donor and acceptor, which are dissolved in one or mixed solvents. Ideally, the donor and acceptor will homogeneously distribute in both lateral and vertical direction through the active layer and they will not gather around one side to transport certain electrons or holes. However, in reality, the distribution of the donor and acceptor within the photoactive layer is inhomogeneous due to the different surface energy and compatibility. The vertical concentration distribution was observed in fullerene based blend systems caused by the surface energy difference [12-17]. Take the P3HT:PC ${ }_{60} \mathrm{BM}$ OSC as an example, it is found that P3HT tends to enrich in the upper section of the photoactive layer due to the relatively lower surface energy $(\gamma)$ of $16.9 \mathrm{mN} / \mathrm{m}$, and a small amount of PCBM phase $(\gamma=45 \mathrm{mN} / \mathrm{m})$ accumulates at the PEDOT:PSS interface [18]. This inhomogeneous distribution can also be found in non-fullerene and all-polymer solar cells such as PBDTTT-C-T:PDI and P3HT:F8TBT blends $[19,20]$, where donors gather at the bottom and electrons enrich on the surface. Obviously, this kind of concentration distribution goes against the carrier transportation for conventional OSCs. While for inverted structure, the kind of component aggregation can offer continuous and unhindered pathways for easily carrier transportation to the corresponding electrode, thus enhancing device performance. Therefore, it is very important to understand the distribution of the donor and acceptor materials within the photoactive layer before choosing the conventional or inverted structure of OSCs. Recently, non-fullerene acceptor based OSCs have attracted increasing attention due to their adjustable energy level, facile synthesis, good solubility and wider absorption in the visible region. Thus, the investigation of concentration distribution in non-fullerene blends is crucial for further performance enhancement.

Herein, we investigate the vertical concentration distribution within the photoactive blend layer based on the non-fullerene acceptor IEICO and polymer donor PBDTTT-ET by time-of-flight secondary-ion mass spectroscopy (TOF-SIMS) and scanning Kelvin probe microscopy (SKPM). We find that the electron acceptor IEICO has lower concentration near the surface while the donor PBDTTT-ET has higher concentration near the surface. This inhomogeneous distribution is harmful to exciton dissociation and carrier transportation for inverted OSCs, but it is helpful for conventional structure, since the component aggregation can facilitate carrier transport to the corresponding electrode and enhance device performance. To confirm the vertical concentration distribution within the non-fullerene based photoactive layer, both conventional and inverted devices are designed and fabricated. For conventional OSCs, PEDOT:PSS and the low-work-function metal Ca are commonly used as anode and cathode interfacial materials, respectively. Since the acidic PEDOT:PSS could etch ITO and the low-work-function metals are sensitive to oxygen and water, resulting device degradation. It demonstrates that appropriate thickness of $\mathrm{NiO}_{x}$ can not only suppress the interfacial energy losses between photoactive layer and ITO anode, but also can improve the stability of OSCs [21]. Thus, to further improve the device performance, air stable solution-processed nickel oxide $\left(\mathrm{NiO}_{x}\right)$ and poly[(9,9-bis(3-((N,N-dimethyl)-N-ethylammonium)-propyl)-2,7-fluorene)-alt-2,7-fluorene)-alt-2,7-(9,9dioctylfluorene)]dibromide (PFN-Br) are employed as anode and cathode interfacial materials, and a promising PCE of $9.12 \%$ is achieved for conventional device with high stability.

\section{Experimental Section}

\subsection{Materials}

Nickel acetate tetrahydrate, Titanium (diisopropoxide) bis (2,4-pentanedionate) (TIPD, 75\% in isopropanol solution) and molybdenum trioxide $\left(\mathrm{MoO}_{3}\right)$ were purchased from Alfa Aesar (Shanghai, China) and used directly without further purification. 1,8-diiodooctane (DIO) was purchased from Tokyo Chemical Industry (TCI). PBDTTT-ET, IEICO and PFN-Br were purchased from Solarmer Materials Inc. (Beijing, China). 


\subsection{Device Fabrication}

The inverted OSCs were fabricated with the structure of ITO/TIPD (or $\mathrm{TiO}_{2}$ )/PBDTTT-ET:IEICO/ $\mathrm{MoO}_{3} / \mathrm{Ag}$. ITO coated glass patterned with $2 \mathrm{~mm}$ width strips was ultrasonic cleaned twice by detergent, water, deionized water, acetone and isopropanol successively. TIPD was diluted by isopropanol for 20 times before spin-coated at a speed of $4000 \mathrm{rpm}$ on the cleaned ITO glass and then baked at $150{ }^{\circ} \mathrm{C}$ for $10 \mathrm{~min}$. Compact $\mathrm{TiO}_{2}$ layer was deposited by spray a $0.15 \mathrm{M}$ titanium diisopropoxide bis(acetylacetonate) precursor solution using oxygen as carrier gas and then pyrolyzed at $450{ }^{\circ} \mathrm{C}$ for $30 \mathrm{~min}$. Then the substrate was transferred into the nitrogen-filled glove-box for the following procedures. The photoactive layer was prepared by spin-coating PBDTTT-ET:IEICO chloroform solution $(1: 1.25 w / w$, polymer concentration of $10 \mathrm{mg} / \mathrm{mL}$ ) with $2 \%$ volume ratio of DIO additive on the ITO/TIPD $\left(\right.$ or $\left.\mathrm{TiO}_{2}\right)$ substrate. The thickness of the PBDTTT-ET:IEICO film is around $100 \mathrm{~nm}$. Then the samples were transferred into a vacuum chamber, and a $10 \mathrm{~nm}$ of $\mathrm{MoO}_{3}$ layer and a $100 \mathrm{~nm}$ of $\mathrm{Ag}$ were thermally deposited on the photoactive layer under a base pressure of $5 \times 10^{-5} \mathrm{~Pa}$. The area of the device is around $4 \mathrm{~mm}^{2}$ defined by perpendicular cross area of ITO and cathode electrode.

For conventional OSCs, the device structure is ITO/ $\mathrm{NiO}_{x}$ (or PEDOT:PSS)/PBDTTT-ET:IEICO/ $\mathrm{PFN}-\mathrm{Br} / \mathrm{Al}$. The pre-cleaned ITO substrate was treated in an ultraviolet-ozone chamber (Ultraviolet Ozone Cleaner, Jelight Company, USA) for $15 \mathrm{~min}$. The $\mathrm{NiO}_{x}$ film was fabricated by spin-coating a nickel acetate tetrahydrate $\left[\mathrm{Ni}\left(\mathrm{CH}_{3} \mathrm{COO}\right)_{2} \cdot 4 \mathrm{H}_{2} \mathrm{O}\right]$ aqueous solution with different concentrations on the pretreated ITO substrate, followed by annealing in air at $150{ }^{\circ} \mathrm{C}$ for $10 \mathrm{~min}$ and UVO treatment for $4 \mathrm{~min}$. PEDOT:PSS aqueous solution was filtered through a $0.45 \mu \mathrm{m}$ filter and spin-coated at $4000 \mathrm{rpm}$ for $30 \mathrm{~s}(30 \mathrm{~nm})$ on the ITO electrode. Subsequently, the PEDOT:PSS film was baked at $150{ }^{\circ} \mathrm{C}$ for $15 \mathrm{~min}$ in air. The photoactive layer was prepared with the same experiment condition as that in the inverted device. Then, a cathode buffer layer of PFN-Br $(1 \mathrm{mg} / \mathrm{mL}$ in methyl alcohol) was spin-coated at $4000 \mathrm{rpm}$ for $30 \mathrm{~s}$ on the photoactive layer. Finally, a $100 \mathrm{~nm}$ of Al was thermally deposited in vacuum under at pressure of $5 \times 10^{-5} \mathrm{~Pa}$.

\subsection{Device Characterization}

The current density-voltage $(J-V)$ measurement of the devices was conducted on a computercontrolled Keithley 2400 Source Measure Unit. $J-V$ tests were done in a glove-box under simulated AM 1.5G irradiation $\left(100 \mathrm{~mW} / \mathrm{cm}^{2}\right)$ using a xenon-lamp-based solar simulator (AAA grade, SAN-EI ELECTRIC Co., Ltd., Osaka, Japan). The external quantum efficiency (EQE) was measured using a Systems model QE-DLI lock-in amplifier coupled with a QE-M110 monochromator and $75 \mathrm{~W}$ xenon lamp (Enli Technology Co., Ltd., Kaohsiung, Taiwan). The light intensity at each wavelength was calibrated with a standard single-crystal Si photovoltaic cell. The EQE tests were performed under ambient condition.

\subsection{Instrumentation}

The surface morphologies of the PBDTTT-ET:IEICO photoactive layer and ITO substrates with different buffer layers were analyzed using an Agilent 5500 atomic force microscope (AFM) (Agilent, Santa Clara, CA, USA) operated in the tapping mode under ambient condition, the scan area was $5 \mu \mathrm{m}$ by $5 \mu \mathrm{m}$. Scanning Kelvin probe microscopy (KPFM) measurements were also carried out on the same AFM using the standard SKPM mode. The secondary ion mass spectrum was obtained using a time-of-flight secondary ion mass spectrometer TOF-SIMS 5 from ION-TOF GmbH (Münster, Germany). An $\mathrm{Ar}^{+}$sputter beam operating at a $5 \mathrm{keV}$ beam voltage with a $45^{\circ}$ incident angle was used. A depth profiling experiment was performed using an analysis beam of $\mathrm{Bi}^{3+}$ at a $30 \mathrm{keV}$ beam voltage with a scanned area of $100 \mu \mathrm{m}$ by $100 \mu \mathrm{m}$ inside an etching area of $300 \mu \mathrm{m}$ by $300 \mu \mathrm{m}$. The absorption and reflectance spectra of $\mathrm{NiO}_{x}$ and PEDOT:PSS modified ITO substrates were measured from 300 to $900 \mathrm{~nm}$ by Shimadzu UV-2450 Spectrophotometer (Shimadzu, Kyoto, Japan). The slit width is $5.00 \mathrm{~nm}$ and scan speed is $300 \mathrm{~nm} / \mathrm{min}$. The reflectivity was measured using a Hitachi UH4150 UV-Vis 
spectrometer (Hitachi, Tokyo, Japan) with an integrating sphere (rectangular integration method). The slit width and scan speed are also $5.00 \mathrm{~nm}$ and $300 \mathrm{~nm} / \mathrm{min}$.

\section{Results and Discussion}

The molecular structures of PBDTTT-ET and IEICO are depicted in Figure 1a,b, respectively. To clarify the donor and acceptor distribution within the photoactive layer, time-of-flight secondary-ion mass spectroscopy (TOF-SIMS) measurements were conducted. TOF-SIMS is a surface analytical technique that focuses a pulsed beam of primary ions onto a sample surface, producing secondary ions in a sputtering process. TOF-SIMS can be used for depth profiling and complements dynamic SIMS. The advantages for profiling are its small areas capabilities and also its ability to do survey depth profiles without selecting specific elements of interest. Since it directly detects intrinsic sputtered secondary ions, TOF-SIMS is more accurate in compared with the traditionally used reflectivity measurements such as X-ray reflectivity (XRR), and neutron reflectivity (NR) [22]. Comparing the molecular structure of PBDTTT-ET with IEICO, nitrogen $(\mathrm{N})$ is the characteristic element of acceptor IEICO, but there is no specific element for donor PBDTTT-ET. So we firstly investigated the characteristic species of PBDTTT-ET and IEICO by TOF-SIMS, and the distribution maps of elements within IEICO and PBDTTT-ET are shown in Figure 1c,d is the local enlarged drawing of Figure 1c. The molecular weight of highest percentage of sulfur isotopes is $31.97, \mathrm{~S}_{2}{ }^{-}$is 63.94 , as shown in Figure $1 \mathrm{~d}$. Hence, $\mathrm{S}_{2}{ }^{-}$and ${ }^{13} \mathrm{CN}^{-}$are the specific species for PBDTTT-ET and IEICO, respectively. Then, we investigated the vertical distribution of $\mathrm{S}_{2}{ }^{-}$and ${ }^{13} \mathrm{CN}^{-}$to explore the aggregation of PBDTTT-ET and IEICO through the photoactive layer by TOF-SIMS. To more directly illustrate the donor and acceptor distribution within the photoactive layer, the distribution is expressed as a percentage, as shown in Figure 1e. It can be seen that the IEICO decreases from $73 \%$ to $28 \%$, while the PBDTTT-ET increases from $67 \%$ to $32 \%$ with the increasing sputter time. To intuitively observe the change of IEICO distribution in the photoactive layer surface, the individual distribution of ${ }^{13} \mathrm{CN}^{-}$(IEICO) on the surface and at the bottom of the active layer is displayed in Figure S1a,b (see Supplementary Materials), respectively, in which the white dots represent ${ }^{13} \mathrm{CN}^{-}$. The peak area of ${ }^{13} \mathrm{CN}^{-}$on the surface and at the bottom are 8382 and 4503 , respectively, which means that the concentration of IEICO on the surface is more than two times higher than that of at the bottom within the photoactive layer. Therefore, from the viewpoint of charge transportation, the PBDTTT-ET:IEICO blend is more suitable for conventional device structure where more IEICO enriches on the top surface, which could benefit electron transport and collection, at the same time, low concentration distribution of IEICO at the bottom could enhance hole transport and collection.

To further confirm the inhomogeneous distribution of donor and acceptor within the photoactive layer could greatly impact on the device performance with different structure, inverted (Figure S2a) and conventional (Figure S2b) OSCs are designed and fabricated. In order to avoid the influence of cathode buffer layer on the performance of inverted OSCs, two common interfacial materials, $\mathrm{TiO}_{2}$ and TIPD, were chosen to incorporate inverted OSCs, whose energy level match well with the PBDTTT-ET:IEICO photoactive layer. For conventional OSCs, PEDOT:PSS and the low-work-function metal Ca are commonly used as anode and cathode interfacial materials. However, the acidic PEDOT:PSS would etch ITO and cause morphology uniformity and chemistry instability [23-25]. The low-work-function metal $\mathrm{Ca}$ is sensitive to oxygen and water, leading to device degradation [26]. Hence, we employed solution-processed $\mathrm{NiO}_{x}$ [27] and PFN-Br [28] as anode and cathode interfacial materials, respectively. 
a
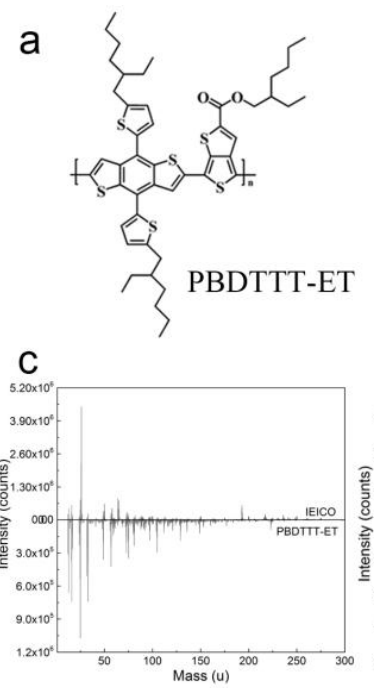

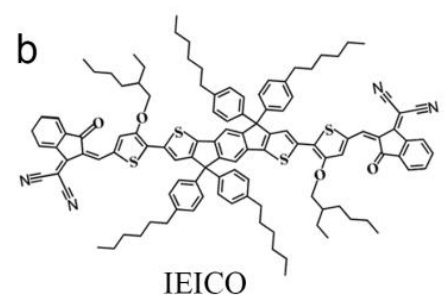

IEICO
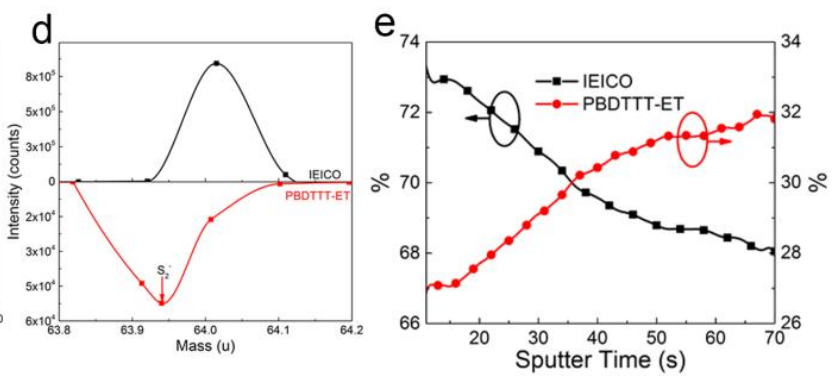

Figure 1. Molecular structures of (a) PBDTTT-ET and (b) IEICO; (c) distribution maps of elements within IEICO and PBDTTT-ET; (d) local enlarged drawing of distribution maps in (c); (e) depth profiles of IEICO and PBDTTT-ET in the blend film.

Figure $2 \mathrm{a}, \mathrm{b}$ gives the energy diagrams of inverted and conventional devices. The electronic energy levels of $\mathrm{TiO}_{2}$ [29], TIPD [30], PBDTTT-ET:IEICO [31] and the work function of $\mathrm{NiO}_{x}$ [27], PEDOT:PSS [32], $\mathrm{MoO}_{3}$ [7] and PFN-Br [4] are taken from literatures. As shown in Figure 2a, the lowest unoccupied molecular orbital (LUMO) of $\mathrm{TiO}_{2}$ is $-4.2 \mathrm{eV}$ which aligns between IEICO (3.95 eV) and ITO $(4.7 \mathrm{eV})$, promoting the electrons transport from IEICO to ITO cathode. The LUMO of TIPD $(-3.9 \mathrm{eV})$ is almost the same as IEICO, thus the electrons can easily transport to the ITO through TIPD. Furthermore, both $\mathrm{TiO}_{2}$ and TIPD have a deep highest occupied molecular orbital (HOMO), -7.4 and $-4.2 \mathrm{eV}$ respectively, which can block the holes transportation and reduce carrier recombination. $\mathrm{MoO}_{3}$ can form an ohmic contact with the PBDTTT-ET donor material due to its high work function of $5.4 \mathrm{eV}$ [33]. Therefore, from the viewpoint of energy level, this kind of inverted OSC is workable. For conventional OSCs as shown in Figure $2 b$, the $\mathrm{NiO}_{x}$ film was prepared by spin-coating aqueous solution of nickel acetate tetrahydrate and then annealed at a low temperature of $150{ }^{\circ} \mathrm{C}$ for $10 \mathrm{~min}$ followed by UVO treated for $4 \mathrm{~min}$, it is denoted as $\alpha-\mathrm{NiO}_{x}$ and o- $\mathrm{NiO}_{x}$ before and after UVO treatment [27]. The o- $\mathrm{NiO}_{x}$ film obtained an increased work function of $4.93 \mathrm{eV}$, much higher than that of $\alpha-\mathrm{NiO}_{x}(4.24 \mathrm{eV})$, resulting in better alignment with the HOMO of PBDTTT-ET and expected to obtain a higher open-circuit voltage $\left(V_{o c}\right)$. With $4.93 \mathrm{eV}$ work function and $2.1 \mathrm{eV}$ electron affinity, $\mathrm{NiO}_{x}$ can not only effectively transport holes, but also block electrons in conventional devices $[27,34,35]$. Meanwhile, PFN-Br can introduce effective interface dipoles to reduce voltage losses $[36,37]$.
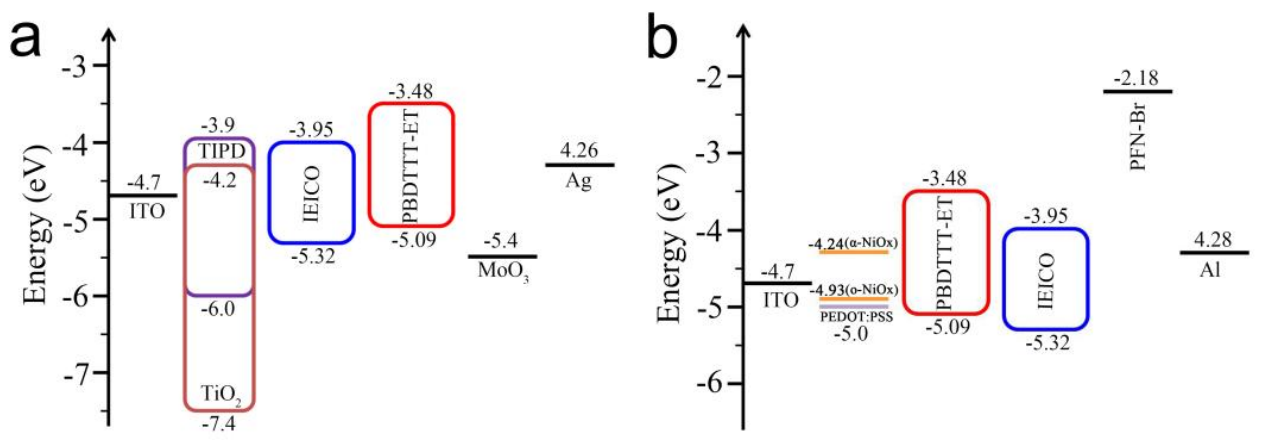

Figure 2. Energy level diagrams of (a) inverted and (b) conventional OSCs. 
The optical, electronic and surface properties of the $\mathrm{NiO}_{x}$ thin films obtained from our approach are also investigated. Figure 3 displays the surface potential and topography morphologies of $\mathrm{NiO}_{x}$ films measured by scanning Kelvin probe microscopy (SKPM) and atomic force microscopy (AFM). During the SKPM measurement, the sample and tip is connected by a $0.5 \mathrm{~mm}$ platinum filament, and a direct current (DC) voltage is applied to the tip. The DC voltage will automatically adjust until the electrostatic force between the surface of the sample and the tip is nullified. In addition, the DC can be calculated by the following formula [38,39].

$$
\mathrm{CPD}=\mathrm{V}_{\mathrm{dc}}=\frac{\varnothing_{\text {tip }}-\varnothing_{\text {sample }}}{\mathrm{q}}
$$

where CPD is the abbreviation of contact potential difference (CPD), q is the electron charge, $\varnothing_{\text {tip }}$ is the tip work function and $\varnothing_{\text {sample }}$ is the work function of measured sample. We can infer from the above formula that the work function is inversely proportional to CPD. The CPD values calculated from Formula (1) for ITO, ITO/PEDOT:PSS and ITO/ $\mathrm{NiO}_{x}$ substrates are 345,215 and $239 \mathrm{mV}$, respectively, as shown in Figure $3 \mathrm{a}-\mathrm{c}$, indicating that the work function of ITO is greatly enhanced with PEDOT:PSS or $\mathrm{NiO}_{x}$ modification, which is more favorable to the formation of ohmic contact between the anode and photoactive layer, thus leading to a higher $V_{o c}$. Furthermore, we utilized a height distribution function, which is computed as normalized histograms of the height values, to illustrate the surface potential differences between ITO, ITO/PEDOT:PSS and ITO/ $\mathrm{NiO}_{x}$ directly, as shown in Figure 3d. Where $\varrho(\mathrm{p})$ is the normalization of the density, and $\mathrm{p}$ is the corresponding quantity height.

$$
\int_{-\infty}^{\infty} \varrho(\mathrm{p}) \mathrm{dp}=1
$$

Observing from the topography morphologies as shown in Figure $3 \mathrm{e}-\mathrm{h}$, we can find that the ITO substrate becomes smoother after modified with $\mathrm{NiO}_{x}$, and the root mean square roughness (RMS) of ITO decreases from 2.26 to $1.39 \mathrm{~nm}$, which is even smoother than that of PEDOT:PSS modified surface $(1.48 \mathrm{~nm})$. The results indicate that a smoother interfacial contact can be obtained between the photoactive layer and anode, which is beneficial to the exciton separation and charge transportation, thus increasing the short-circuit current density $\left(J_{s c}\right)$ [40]. We also calculated the height distribution of AFM topography images with the same statistical function as the Formula (2), and the result is shown in Figure 3h. Obviously, the $\mathrm{NiO}_{x}$ modified surface demonstrates the lowest surface roughness.
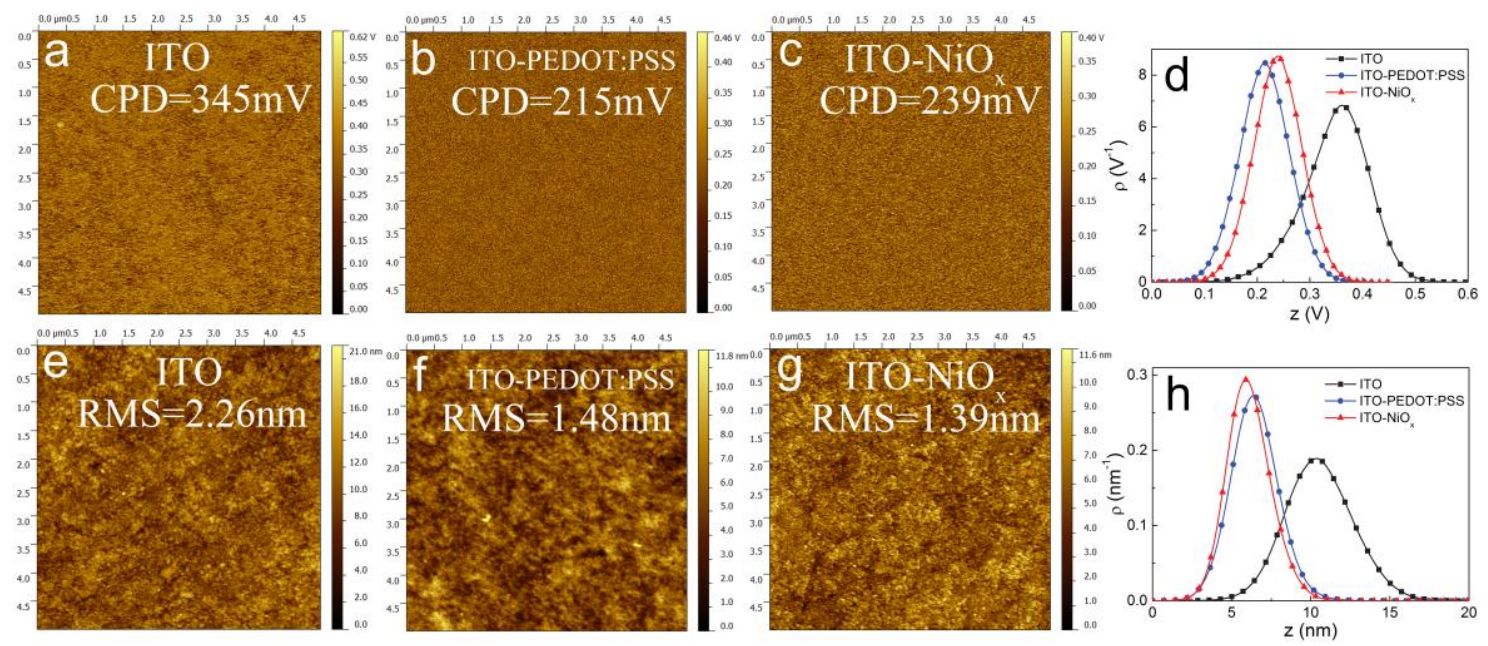

Figure 3. Contact potentials and AFM topography images of $(\mathbf{a}, \mathbf{e})$ ITO, $(\mathbf{b}, \mathbf{f})$ ITO/PEDOT:PSS and $(\mathbf{c}, \mathbf{g})$ $\mathrm{ITO} / \mathrm{NiO}_{x}(1.5 \mathrm{mg} / \mathrm{mL})$; The normalization of the height density distributions of $(\mathbf{d})$ contact potentials and (h) AFM topography images. 
As anode interfacial material, apart from the surface properties, optical characteristics of $\mathrm{NiO}_{x}$ are equally important. Thus, we carried out the absorption and transmission tests and the results are shown in Figure 4, the inset is the local enlarged image (340-390 nm) of bare ITO and different concentration $\mathrm{NiO}_{x}$ coated ITO. In comparison with bare ITO substrate without any modification layer, the absorption of $\mathrm{NiO}_{x}$ coated ITO substrate is almost unchanged in the whole visible wavelength range. The corresponding transmittance is basically unchanged in addition to a slight increase in the short wavelength, and still maintains a high degree of transparency in the visible and near-infrared region, with an average transmittance of about $85 \%$. In the short wavelength of $350-450 \mathrm{~nm}$, the PEDOT:PSS coated ITO is more transmissive than that of bare ITO. Such anti-reflection effect should be attributed to the optical interference between the organic layer (PEDOT-PSS) and inorganic (ITO) layer due to their large refractive index (n) difference [41]. Compared with PEDOT:PSS film, the $\mathrm{NiO}_{x}$ film even has lower absorption and higher transmittance in 650-900 nm wavelength range due to the different optical constants of organic and inorganic materials. Furthermore, as depicted in the inset figure, fine-tune the concentration of $\mathrm{NiO}_{x}$ from 1 to $2 \mathrm{mg} / \mathrm{mL}$ has little influence on the absorption and transmittance. This satisfactory property lays a good optical foundation for the application of $\mathrm{NiO}_{x}$ as anode interfacial material in OSCs.

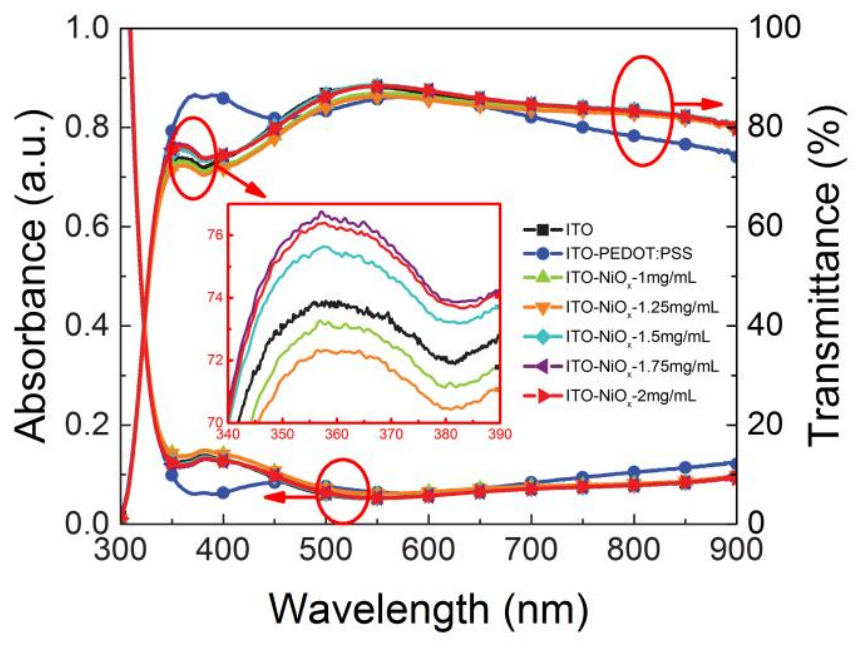

Figure 4. Optical absorption and transmittance spectra of ITO, ITO/PEDOT:PSS and ITO/NiO $x$ (with different concentration) substrates, the inset is the local enlarged image of $340-390 \mathrm{~nm}$.

The current density-voltage $(J-V)$ curves and external quantum efficiency (EQE) curves of OSCs with different device structures are shown in Figure 5. The key performance parameters of $V_{o c}, J_{s c}$, filling factor (FF) and PCE are summarized in Table 1. As displayed in Figure 5a, under illumination, the inverted OSC with TIPD as the buffer layer exhibits an average PCE of $6.26 \%$, with a $V_{o c}$ of $0.81 \mathrm{~V}$, a $J_{s c}$ of $14.48 \mathrm{~mA} / \mathrm{cm}^{2}$ and an $\mathrm{FF}$ of $53.6 \%$, and the $\mathrm{TiO}_{2}$-based device shows a higher $J_{s c}$ of $16.01 \mathrm{~mA} / \mathrm{cm}^{2}$, a same $V_{o c}$ of $0.81 \mathrm{~V}$, a similar FF of $52.8 \%$ and an overall PCE of $6.86 \%$. As presented in Figure $5 b$, the integrated $J_{s c}$ calculated from EQE curves are 11.31 and $11.74 \mathrm{~mA} / \mathrm{cm}^{2}$ respectively for TIPD and $\mathrm{TiO}_{2}$-based devices, and there is some mismatch between the $J_{s c}$ obtained from $J-V$ curve and the integrated current calculated from EQE curve, which is probably due to the inside defects of the photoactive layer [42-44]. To further understand the cause of the differences between the efficiencies of conventional and inverted devices, IQE is given by IQE $=\mathrm{EQE} /(1-\mathrm{R})$, where EQE is the external quantum efficiency and $R$ is the reflectivity, as shown in Figure S3. The IQE is inversely related to the amount of recombination that is occurring in the cell. As shown in Figure S3, the IQE of conventional OSC exhibits a high IQE about $80 \%$ from 500 to $850 \mathrm{~nm}$ and much higher than that of inverted one, which validates the efficient photon conversion properties of conventional OSC. Furthermore, the surface morphology of PBDTTT-ET:IEICO photoactive layer deposited on 
ITO/TIPD and ITO/PEDOT:PSS substrates are investigated by AFM measurements as shown in Figure S4. We can see that the height and phase morphologies of ITO/TIPD/PBDTTT-ET:IEICO and ITO/PEDOT:PSS/PBDTTT-ET:IEICO are remain similar, and the RMS is 6.05 and $6.02 \mathrm{~nm}$, respectively, and the difference is negligible. As we can see from 3D views in Figure S4, the crystallization of conventional and inverted photoactive layer in the upper $50 \mathrm{~nm}$ shows no significant difference. These observations confirm that the performance differences between the conventional and inverted devices are not due to the morphology difference.

Table 1. Device parameters of OSCs with different structure and different buffer layers.

\begin{tabular}{lccccc}
\hline \multicolumn{2}{c}{ Device Structure } & $J_{\boldsymbol{s c}}\left(\mathbf{m A} / \mathbf{c m}^{\mathbf{2}}\right)$ & $V_{\boldsymbol{o c}}(\mathrm{V})$ & FF (\%) & PCE (\%) Average ${ }^{\mathbf{1}}$ \\
\hline \multirow{2}{*}{ Inverted } & $\mathrm{TIPD}$ & 14.48 & 0.81 & 53.6 & $6.26(6.15)$ \\
& $\mathrm{TiO}_{2}$ & 16.01 & 0.81 & 52.8 & $6.86(6.73)$ \\
\hline \multirow{3}{*}{ Conventional } & None & 14.89 & 0.69 & 52.9 & $5.43(5.24)$ \\
& $\mathrm{PEDOT}^{\text {PSS }}$ & 16.54 & 0.82 & 65.1 & $8.83(8.77)$ \\
& $\mathrm{NiO}_{x}$ & 17.52 & 0.81 & 64.3 & $9.12(9.06)$ \\
\hline
\end{tabular}

${ }^{1}$ The average values were obtained from 20 devices.

Figure $5 c, d$ illustrates the $J-V$ and EQE curves of conventional OSCs with different anode buffer layers. As depicted in Figure $5 c$, the control device without anode buffer layer shows a $J_{s c}$ of $14.89 \mathrm{~mA} / \mathrm{cm}^{2}$, a $V_{o c}$ of $0.69 \mathrm{~V}$ and an FF of $52.9 \%$, leading to an overall PCE of $5.43 \%$. For device with PEDOT:PSS as anode buffer layer, the better performance can be achieved, with a $J_{s c}$ of $16.54 \mathrm{~mA} / \mathrm{cm}^{2}$, a $V_{o c}$ of $0.82 \mathrm{~V}$, an FF of $65.1 \%$, and a PCE of $8.83 \%$. As expected, the device with $\mathrm{NiO}_{x}$ anode buffer layer shows the best PCE of $9.12 \%$, with a $V_{o c}$ of $0.81 \mathrm{~V}$, a $J_{s c}$ of $17.52 \mathrm{~mA} / \mathrm{cm}^{2}$ and an FF of $64.3 \%$. Compared with the PEDOT:PSS based device, the PCE improvement for $\mathrm{NiO}_{x}$ based device is mainly ascribed to the $J_{s c}$ enhancement, and the $J_{s c}$ enhancement should be attributed to the optical spacer effect induced by $\mathrm{NiO}_{x}$ film due to different optical constants of organic and inorganic materials [45-47]. The $\mathrm{NiO}_{x}$ film can modulate the light distribution within the whole active layer, subsequently impact the $J_{s c}$. Figure $5 \mathrm{~d}$ gives the EQE curves of conventional OSCs with different buffer layers. The integrated $J_{s c}$ calculated from EQE curves are 14.04, 16.49 and $17.52 \mathrm{~mA} / \mathrm{cm}^{2}$ for the devices without any anode buffer layer, with PEDOT:PSS and $\mathrm{NiO}_{x}$ as anode buffer layer, respectively, which is in good agreement with the $J_{s c}$ obtained from $J-V$ curves. The OSCs with anode buffer layers show much higher EQE than that of OSCs without anode buffer layer in almost the whole wavelength which is consistent with the higher $J_{s c}$. Furthermore, the $\mathrm{NiO}_{x}$ OSC obtains the highest integrated current of $17.52 \mathrm{~mA} / \mathrm{cm}^{2}$, and the EQE enhancement is mainly in 300-500 $\mathrm{nm}$ and $575-900 \mathrm{~nm}$ spectral ranges.

Obviously, the device performances of conventional structure are much higher than that of inverted ones. This is an indirect evidence of the aforementioned vertical concentration distribution as shown in Figure S2, since more IEICO gathers on the top surface and low concentration of IEICO distributes at the bottom, which could benefit charges transport and collection, resulting higher performance of conventional devices.

Furthermore, we carefully tuned the thickness of $\mathrm{NiO}_{x}$ film to further optimize the device performance. The $J-V$ and EQE curves of OSCs with different thickness of $\mathrm{NiO}_{x}$ layers are given in Figure $5 \mathrm{e}, \mathrm{f}$, and the key performance parameters are summarized in Table 2. With increasing concentration of $\mathrm{NiO}_{x}$, the $J_{s c}$ increases first and then remains at a certain level, the $V_{o c}$ is almost constant and the FF increases first and then decrease. Actually, tuning the thickness of $\mathrm{NiO}_{x}$ layer is finding the tradeoff between the charge transport and surface coverage. Too thinner film cannot cover the whole ITO surface and too thicker film should increase the contact resistance. An overall optimal PCE of $9.12 \%$ was achieved at a concentration of $1.5 \mathrm{mg} / \mathrm{mL}$, with a $V_{o c}$ of $0.81 \mathrm{~V}$, a $J_{s c}$ of $17.52 \mathrm{~mA} / \mathrm{cm}^{2}$ and an FF of $64.3 \%$. As depicted in Figure $5 \mathrm{f}$, the integrated $J_{s c}$ calculated from EQE curves is 16.38, $16.50,17.50,17.22$ and $17.39 \mathrm{~mA} / \mathrm{cm}^{2}$ respectively for devices with $1,1.25,1.51 .75$ and $2 \mathrm{mg} / \mathrm{mL} \mathrm{NiO}_{x}$, which is consistent with the $J_{s c}$ value obtained from the $J-V$ curves of the corresponding devices. 

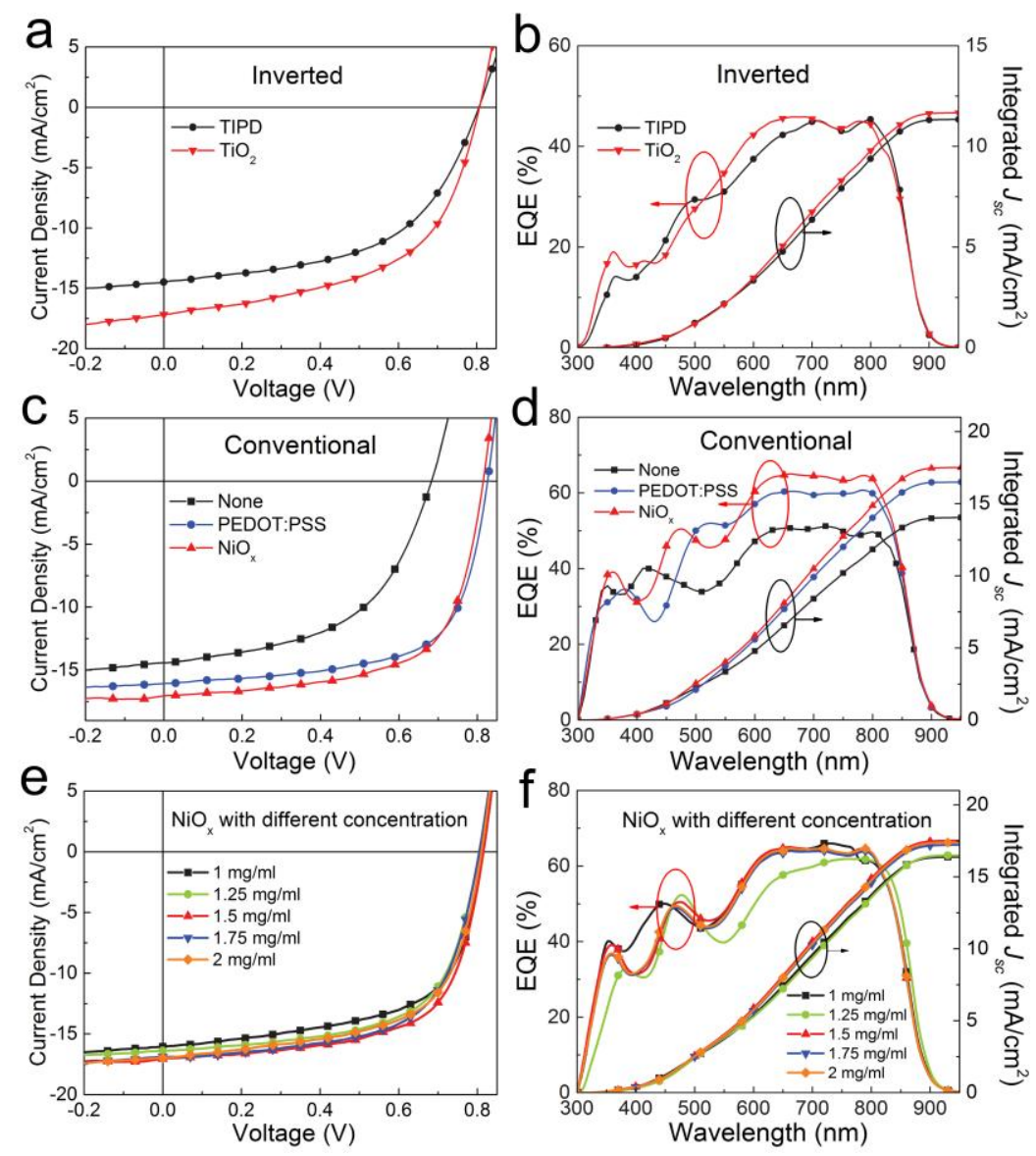

Figure 5. (a) Current density-voltage $(J-V)$ and (b) EQE curves of inverted OSCs with TIPD and $\mathrm{TiO}_{2}$ as cathode buffer layers; (c) $J-V$ and (d) EQE curves of conventional OSCs without anode buffer layer, with PEDOT:PSS and with $\mathrm{NiO}_{x}$ as anode buffer layers; (e) $J-V$ and (f) EQE curves of conventional OSCs with different thickness of $\mathrm{NiO}_{x}$ film as the anode buffer layer.

Table 2. Device parameters of OSCs with different thickness of $\mathrm{NiO}_{x}$ layer as the anode buffer layer.

\begin{tabular}{ccccc}
\hline $\mathbf{N i O}_{x}$ Concentration $(\mathbf{m g} / \mathbf{m L})$ & $J_{s c}\left(\mathbf{m A} / \mathbf{c m}^{2}\right)$ & $V_{o c}(\mathrm{~V})$ & FF (\%) & PCE (\%) Average ${ }^{\mathbf{1}}$ \\
\hline 1 & 16.38 & 0.81 & 59.7 & $7.92(7.79)$ \\
1.25 & 16.50 & 0.80 & 62.1 & $8.20(8.11)$ \\
1.5 & 17.52 & 0.81 & 64.3 & $9.12(9.06)$ \\
1.75 & 17.37 & 0.80 & 62.4 & $8.68(8.47)$ \\
2 & 17.46 & 0.80 & 60.5 & $8.46(8.32)$ \\
\hline
\end{tabular}

${ }^{1}$ The average values were obtained from 20 devices.

Since we employed $\mathrm{NiO}_{x}$ film to substitute the acidic and hydrophilic PEDOT:PSS, the OSCs should have a better stability as expected. Thus, long-term stability of unencapsulated OSCs fabricated with PEDOT:PSS and $\mathrm{NiO}_{x}$ anode buffer layers were investigated by testing the device performance every $24 \mathrm{~h}$ in $\mathrm{N}_{2}$ filled glove box. Figure 6 shows the degradation behaviors of the normalized PCEs of both devices. It can be seen that OSCs with $\mathrm{NiO}_{x}$ buffer layer demonstrated better stability. For the devices based on PEDOT:PSS buffer layer, the PCE drops to less than 70\% of its initial value, while the OSCs based on $\mathrm{NiO}_{x}$ buffer layer still remains $85 \%$ initial value after 16 days. The stability improvement can be attributed to the optimized interface between anode and photoactive layer. Therefore, $\mathrm{NiO}_{x}$ was demonstrated a promising anode buffer layer for enhancing the environmental stability of solution-processed OSCs. 


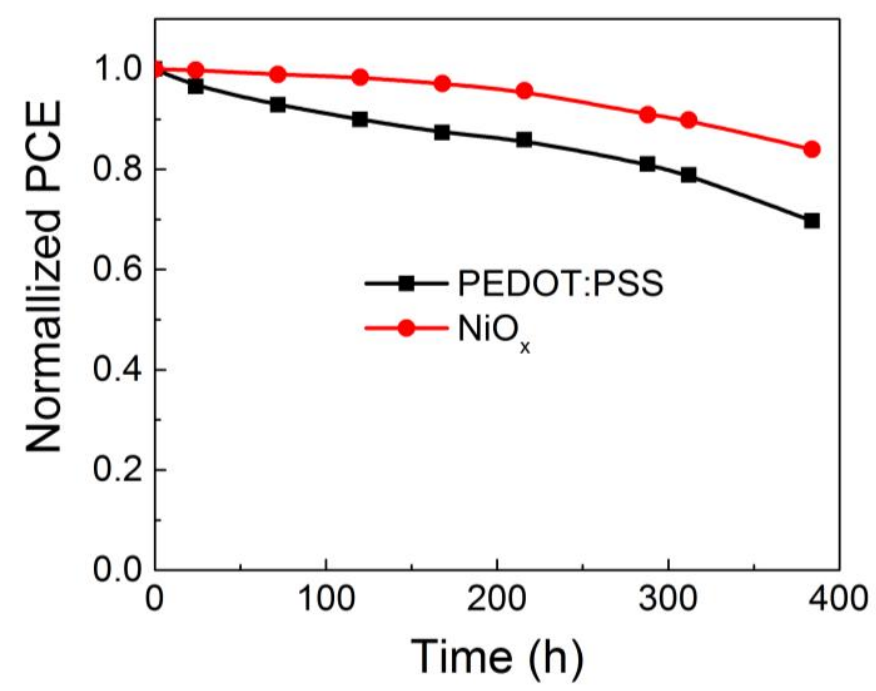

Figure 6. Long-term stability of the PCE for unencapsulated OSCs based on either PEDOT:PSS or $\mathrm{NiO}_{x}$ anode buffer layers. The devices have been stored in $\mathrm{N}_{2}$ filled glove box.

\section{Conclusions}

In conclusion, we have confirmed there is vertical concentration distribution within the nonfullerene based photoactive layer PBDTTT-ET:IEICO by TOF-SIMS measurements and device characterization. TOF-SIMS results indicate that the acceptor IEICO enriches on the top surface and the donor PBDTTT-ET uniformly distributes throughout the photoactive layer. This spontaneous vertical concentration distribution favors the charge transportation of device with conventional structure, and OSCs with conventional structure show significant enhancements in $J_{s c}$ and FF, leading to a $41 \%$ enhancement in PCE compared with the inverted ones. More stable and efficient devices have been achieved by introducing solution-processed $\mathrm{NiO}_{x}$ as anode interfacial material in conventional OSCs. Compared with PEDOT:PSS based devices, $\mathrm{NiO}_{x}$ based devices demonstrate increased $J_{s c}$ and longer lifetime, the $J_{s c}$ increases from 16.54 to $17.52 \mathrm{~mA} / \mathrm{cm}^{2}$ due to the increasing charge extraction efficiency, and the PCE still remains $85 \%$ of its initial value after stored for 16 days, while the PEDOT:PSS based OSCs decays to below 70\% of its initial value. Our findings indicate that, based on the inhomogeneous distribution of donor and acceptor materials within the photoactive layer, properly selection the conventional or inverted device structure is crucial for effective exciton dissociation and charge transportation. Furthermore, solution-processed $\mathrm{NiO}_{x}$ is a promising alternative to PEDOT:PSS for fabrication of efficient and stable OSCs.

Supplementary Materials: The following are available online at www.mdpi.com/2073-4360/9/11/571/s1, Figures S1-S4.

Acknowledgments: This work was supported by the NSFC (51573042), The National Key Basic Research Program of China (973 project, 2015CB932201), Fundamental Research Funds for the Central Universities, China (JB2015RCJ02, 2016YQ06, 2016MS50, 2016XS47).

Author Contributions: Yaping Wang and Zhan'ao Tan conceived and designed the experiments; Yaping Wang performed the experiments; Yaping Wang, Zhenzhen Shi, Hao Liu, Fuzhi Wang, Yiming Bai, Xingming Bian and Bing Zhang analyzed the data; Tasawar Hayat and Ahmed Alsaedi contributed reagents/materials/analysis tools; Yaping Wang and Zhan'ao Tan wrote the paper.

Conflicts of Interest: The authors declare no conflict of interest. 


\section{References}

1. Chopra, K.L.; Paulson, P.D.; Dutta, V. Thin-film solar cells: An overview. Prog. Photovolt. 2004, 12, 69-92. [CrossRef]

2. Liu, Y.; Chen, C.C.; Hong, Z.; Gao, J.; Yang, Y.M.; Zhou, H.; Dou, L.; Li, G.; Yang, Y. Solution-processed small-molecule solar cells: Breaking the 10\% power conversion efficiency. Sci. Rep. 2013, 3, 3356. [CrossRef] [PubMed]

3. Wang, Y.; Zhu, H.; Shi, Z.; Wang, F.; Zhang, B.; Dai, S.; Tan, Z.A. Engineering the vertical concentration distribution within the polymer:Fullerene blends for high performance inverted polymer solar cells. J. Mater. Chem. A 2017, 5, 2319-2327. [CrossRef]

4. Fan, B.; Zhang, K.; Jiang, X.F.; Ying, L.; Huang, F.; Cao, Y. High-performance nonfullerene polymer solar cells based on imide-functionalized wide-bandgap polymers. Adv. Mater. 2017, 29. [CrossRef] [PubMed]

5. Zhao, W.; Li, S.; Yao, H.; Zhang, S.; Zhang, Y.; Yang, B.; Hou, J. Molecular optimization enables over 13\% efficiency in organic solar cells. J. Am. Chem. Soc. 2017. [CrossRef] [PubMed]

6. Marrocchi, A.; Facchetti, A.; Lanari, D.; Petrucci, C.; Vaccaro, L. Current methodologies for a sustainable approach to $\pi$-conjugated organic semiconductors. Energy Environ. Sci. 2016, 9, 763-786. [CrossRef]

7. He, Z.; Zhong, C.; Su, S.; Xu, M.; Wu, H.; Cao, Y. Enhanced power-conversion efficiency in polymer solar cells using an inverted device structure. Nat. Photonics 2012, 6, 591-595. [CrossRef]

8. Zhou, Y.; Kurosawa, T.; Ma, W.; Guo, Y.; Fang, L.; Vandewal, K.; Diao, Y.; Wang, C.; Yan, Q.; Reinspach, J.; et al. High performance all-polymer solar cell via polymer side-chain engineering. Adv. Mater. 2014, 26, 3767-3772. [CrossRef] [PubMed]

9. Bin, H.; Zhang, Z.-G.; Gao, L.; Chen, S.; Zhong, L.; Xue, L.; Yang, C.; Li, Y. Non-fullerene polymer solar cells based on alkylthio and fluorine substituted 2D-conjugated polymers reach 9.5\% efficiency. J. Am. Chem. Soc. 2016, 138, 4657-4664. [CrossRef] [PubMed]

10. Takai, A.; Chen, Z.; Yu, X.; Zhou, N.; Marks, T.J.; Facchetti, A. Annulated thienyl-vinylene-thienyl building blocks for $\pi$-conjugated copolymers: Ring dimensions and isomeric structure effects on $\pi$-conjugation length and charge transport. Chem. Mater. 2016, 28, 5772-5783. [CrossRef]

11. Zhao, F.; Dai, S.; Wu, Y.; Zhang, Q.; Wang, J.; Jiang, L.; Ling, Q.; Wei, Z.; Ma, W.; You, W.; et al. Single-junction binary-blend nonfullerene polymer solar cells with $12.1 \%$ efficiency. Adv. Mater. 2017, 29. [CrossRef] [PubMed]

12. Germack, D.S.; Chan, C.K.; Hamadani, B.H.; Richter, L.J.; Fischer, D.A.; Gundlach, D.J.; DeLongchamp, D.M. Substrate-dependent interface composition and charge transport in films for organic photovoltaics. Appl. Phys. Lett. 2009, 94, 233303. [CrossRef]

13. Jo, J.; Na, S.-I.; Kim, S.-S.; Lee, T.-W.; Chung, Y.; Kang, S.-J.; Vak, D.; Kim, D.-Y. Three-dimensional bulk heterojunction morphology for achieving high internal quantum efficiency in polymer solar cells. Adv. Funct. Mater. 2009, 19, 2398-2406. [CrossRef]

14. Jeon, I.I.; Matsuo, Y. Vertical phase separation and light-soaking effect improvements by photoactive layer spin coating initiation time control in air-processed inverted organic solar cells. Sol. Energy Mater. Sol. Cell 2015, 140, 335-343. [CrossRef]

15. Yan, Y.; Liu, X.; Wang, T. Conjugated-polymer blends for organic photovoltaics: Rational control of vertical stratification for high performance. Adv. Mater. 2017, 29. [CrossRef] [PubMed]

16. Kiel, J.W.; Kirby, B.J.; Majkrzak, C.F.; Maranville, B.B.; Mackay, M.E. Nanoparticle concentration profile in polymer-based solar cells. Soft Matter 2010, 6, 641-646. [CrossRef]

17. Parnell, A.J.; Dunbar, A.D.F.; Pearson, A.J.; Staniec, P.A.; Dennison, A.J.C.; Hamamatsu, H.; Skoda, M.W.A.; Lidzey, D.G.; Jones, R.A.L. Depletion of pcbm at the cathode interface in P3HT/PCBM thin films as quantified via neutron reflectivity measurements. Adv. Mater. 2010, 22, 2444-2447. [CrossRef] [PubMed]

18. Germack, D.S.; Chan, C.K.; Kline, R.J.; Fischer, D.A.; Gundlach, D.J.; Toney, M.F.; Richter, L.J.; DeLongchamp, D.M. Interfacial segregation in polymer/fullerene blend films for photovoltaic devices. Macromolecules 2010, 43, 3828-3836. [CrossRef]

19. Vaynzof, Y.; Brenner, T.J.K.; Kabra, D.; Sirringhaus, H.; Friend, R.H. Compositional and morphological studies of polythiophene/polyflorene blends in inverted architecture hybrid solar cells. Adv. Funct. Mater. 2012, 22, 2418-2424. [CrossRef] 
20. Lu, Z.; Jiang, B.; Zhang, X.; Tang, A.; Chen, L.; Zhan, C.; Yao, J. Perylene-Diimide based non-fullerene solar cells with $4.34 \%$ efficiency through engineering surface donor/acceptor compositions. Chem. Mater. 2014, 26, 2907-2914. [CrossRef]

21. Irwin, M.D.; Buchholz, D.B.; Hains, A.W.; Chang, R.P.H.; Marks, T.J. p-Type semiconducting nickel oxide as an efficiency-enhancing anode interfacial layer in polymer bulk-heterojunction solar cells. Proc. Natl. Acad. Sci. USA 2008, 105, 2783-2787. [CrossRef]

22. Ruderer, M.A.; Guo, S.; Meier, R.; Chiang, H.-Y.; Körstgens, V.; Wiedersich, J.; Perlich, J.; Roth, S.V.; Müller-Buschbaum, P. Solvent-induced morphology in polymer-based systems for organic photovoltaics. Adv. Funct. Mater. 2011, 21, 3382-3391. [CrossRef]

23. Dang, X.-D.; Dante, M.; Nguyen, T.-Q. Morphology and conductivity modification of poly(3,4ethylenedioxythiophene):Poly(styrene sulfonate) films induced by conductive atomic force microscopy measurements. Appl. Phys. Lett. 2008, 93, 241911. [CrossRef]

24. Norrman, K.; Gevorgyan, S.A.; Krebs, F.C. Water-induced degradation of polymer solar cells studied by $\mathrm{H}_{2}{ }^{18} \mathrm{O}$ labeling. ACS Appl. Mater. Interfaces 2009, 1, 102-112. [CrossRef] [PubMed]

25. Norrman, K.; Madsen, M.V.; Gevorgyan, S.A.; Krebs, F.C. Degradation patterns in water and oxygen of an inverted polymer solar cell. J. Am. Chem. Soc. 2010, 132, 16883-16892. [CrossRef] [PubMed]

26. Jørgensen, M.; Norrman, K.; Krebs, F.C. Stability/degradation of polymer solar cells. Sol. Energy Mater. Sol. Cell 2008, 92, 686-714. [CrossRef]

27. Wang, F.; Sun, G.; Li, C.; Liu, J.; Hu, S.; Zheng, H.; Tan, Z.; Li, Y. Finding the lost open-circuit voltage in polymer solar cells by UV-ozone treatment of the nickel acetate anode buffer layer. ACS Appl. Mater. Interfaces 2014, 6, 9458-9465. [CrossRef] [PubMed]

28. Yang, T.; Wang, M.; Duan, C.; Hu, X.; Huang, L.; Peng, J.; Huang, F.; Gong, X. Inverted polymer solar cells with $8.4 \%$ efficiency by conjugated polyelectrolyte. Energy Environ. Sci. 2012, 5, 8208. [CrossRef]

29. Gao, P.; Grätzel, M.; Nazeeruddin, M.K. Organohalide lead perovskites for photovoltaic applications. Energy Environ. Sci. 2014, 7, 2448-2463. [CrossRef]

30. Tan, Z.; Zhang, W.; Zhang, Z.; Qian, D.; Huang, Y.; Hou, J.; Li, Y. High-performance inverted polymer solar cells with solution-processed titanium chelate as electron-collecting layer on ITO electrode. Adv. Mater. 2012, 24, 1476-1481. [CrossRef] [PubMed]

31. Yao, H.; Chen, Y.; Qin, Y.; Yu, R.; Cui, Y.; Yang, B.; Li, S.; Zhang, K.; Hou, J. Design and synthesis of a low bandgap small molecule acceptor for efficient polymer solar cells. Adv. Mater. 2016, 28, 8283-8287. [CrossRef] [PubMed]

32. Li, C.; Zhu, H.; Wang, Y.; Liu, H.; Hu, S.; Wang, F.; Zhang, B.; Dai, S.; Tan, Z.A. High performance polymer solar cells with electron extraction and light-trapping dual functional cathode interfacial layer. Nano Energy 2017, 31, 201-209. [CrossRef]

33. Wang, F.; Zhang, B.; Li, Q.; Shi, Z.; Yu, L.; Liu, H.; Wang, Y.; Dai, S.; Tan, Z.A.; Li, Y. Management of the light distribution within the photoactive layer for high performance conventional and inverted polymer solar cells. J. Mater. Chem. A 2016, 4, 1915-1922. [CrossRef]

34. Tan, Z.; Zhang, W.; Qian, D.; Cui, C.; Xu, Q.; Li, L.; Li, S.; Li, Y. Solution-processed nickel acetate as hole collection layer for polymer solar cells. Phys. Chem. Chem. Phys. 2012, 14, 14217-14223. [CrossRef] [PubMed]

35. Zhang, W.; Tan, Z.A.; Qian, D.; Xu, Q.; Li, L.; Li, S.; Wang, F.; Zheng, H.; Li, Y. Using water-soluble nickel acetate as hole collection layer for stable polymer solar cells. J. Appl. Polym. Sci. 2013, 128, 684-690. [CrossRef]

36. Huang, F.; Wu, H.; Wang, D.; Yang, W.; Cao, Y. Novel electroluminescent conjugated polyelectrolytes based on polyfluorene. Chem. Mater. 2004, 16, 708-716. [CrossRef]

37. He, Z.; Zhong, C.; Huang, X.; Wong, W.Y.; Wu, H.; Chen, L.; Su, S.; Cao, Y. Simultaneous enhancement of open-circuit voltage, short-circuit current density, and fill factor in polymer solar cells. Adv. Mater. 2011, 23, 4636-4643. [CrossRef] [PubMed]

38. Lian, C.; Xing, H. Surface potential measurements on $\mathrm{Ni}-(\mathrm{Al})$ gan lateral schottky junction using scanning kelvin probe microscopy. Appl. Phys. Lett. 2006, 88, 022112. [CrossRef]

39. Wang, J.; Fei, F.; Luo, Q.; Nie, S.; Wu, N.; Chen, X.; Su, W.; Li, Y.; Ma, C.Q. Modification of the highly conductive PEDOT:PSS layer for use in silver nanogrid electrodes for flexible inverted polymer solar cells. ACS Appl. Mater. Interfaces 2017, 9, 7834-7842. [CrossRef] [PubMed] 
40. Zhao, G.; He, Y.; Li, Y. 6.5\% efficiency of polymer solar cells based on poly(3-hexylthiophene) and indene- $\mathrm{C}_{60}$ bisadduct by device optimization. Adv. Mater. 2010, 22, 4355-4358. [CrossRef] [PubMed]

41. Hou, X.; Li, Q.; Cheng, T.; Yu, L.; Wang, F.; Lin, J.; Dai, S.; Li, Y.; Tan, Z.A. Improvement of the power conversion efficiency and long term stability of polymer solar cells by incorporation of amphiphilic nafion doped PEDOT-PSS as a hole extraction layer. J. Mater. Chem. A 2015, 3, 18727-18734. [CrossRef]

42. Luther, J.M.; Law, M.; Beard, M.C.; Song, Q.; Reese, M.O.; Ellingson, R.J.; Nozik, A.J. Schottky solar cells based on colloidal nanocrystal films. Nano Lett. 2008, 8, 3488-3492. [CrossRef] [PubMed]

43. Mayer, A.C.; Scully, S.R.; Hardin, B.E.; Rowell, M.W.; McGehee, M.D. Polymer-based solar cells. Mater. Today 2007, 10, 28-33. [CrossRef]

44. Shrotriya, V.; Li, G.; Yao, Y.; Moriarty, T.; Emery, K.; Yang, Y. Accurate measurement and characterization of organic solar cells. Adv. Funct. Mater. 2006, 16, 2016-2023. [CrossRef]

45. Steirer, K.X.; Ndione, P.F.; Widjonarko, N.E.; Lloyd, M.T.; Meyer, J.; Ratcliff, E.L.; Kahn, A.; Armstrong, N.R.; Curtis, C.J.; Ginley, D.S.; et al. Enhanced efficiency in plastic solar cells via energy matched solution processed $\mathrm{NiO}_{x}$ interlayers. Adv. Energy Mater. 2011, 1, 813-820. [CrossRef]

46. Kettle, J.; Waters, H.; Horie, M.; Chang, S.W. Effect of hole transporting layers on the performance of PCPDTBT:PCBM organic solar cells. J. Phys. D Appl. Phys. 2012, 45, 125102. [CrossRef]

47. $\mathrm{Pu}, \mathrm{N}$; $\mathrm{Li}, \mathrm{H} . ; \mathrm{Xie}, \mathrm{L}$. Influence of $\mathrm{NiO}_{x}$ hole-transporting layer on the light absorption of the polymer solar cells. Acta Phys. Sin. 2014, 63. [CrossRef]

(C) 2017 by the authors. Licensee MDPI, Basel, Switzerland. This article is an open access article distributed under the terms and conditions of the Creative Commons Attribution (CC BY) license (http://creativecommons.org/licenses/by/4.0/). 